\title{
Non-destructive evaluation of wild birds under field conditions indicate cues of inter and intra specific competition
}

\author{
Mylswamy Mahendiran ${ }^{1}$ and Parthiban Mylswamy ${ }^{2}$ \\ ${ }^{1}$ Salim Ali Center for Ornithology and Natural History \\ ${ }^{2}$ Affiliation not available
}

May 5, 2020

\begin{abstract}
Digital images have become cheap, yet its perspective issues cause hindrance for size and shape estimations. Here, we quantified shape distortions due to projective issues using Cardboard model fishes. We identified that Generalized Procrustes Analysis preserves shape homogeneity where objects differ in angle up to $20^{\circ}$ are grouped as similar ones. For $2 \mathrm{D}$ shape analysis, the proposed novel filter criterion aids in profitable use of images with minor projective issues. Using the proposed filter criterion images of free ranging Painted Storks (Mycteria leucocephala), taken under field conditions, were subjected for shape analysis. Our result indicates that a subtle difference was noted in the mandibular shape of Painted Storks between two habitats viz., Delhi Zoo and Keoladeo National Park, which indicates a cue of intra and interspecific competition. This study deserve merits as the entire exercise has been done without disturbing or capturing birds which highlights the value of animal welfare.
\end{abstract}

\section{Hosted file}

Interspecific Main -.doc available at https://authorea.com/users/300177/articles/429861-nondestructive-evaluation-of-wild-birds-under-field-conditions-indicate-cues-of-inter-andintra-specific-competition 